\title{
A REESTRUTURAÇÃo PROdUTIVA E A CONTRATAÇÃo TEMPORÁRIA DE DOCENTES NAS REDES PÚBLICAS NO BRASIL
}

\section{PRODUCTIVE RESTRUCTURING AND TEMPORARY HIRING OF TEACHERS ON THE BRAZILIAN PUBLIC SCHOOLS}

\section{RESUMO}

\author{
Denize Cristina Kaminski Ferreira ${ }^{1}$
}

A forma convencional de ingresso no setor público no Brasil se consolidou por meio da aprovação em concurso, o que garante estabilidade profissional ao trabalhador, entretanto, a tendência global de flexibilização das contratações, que se iniciou no setor produtivo e, paulatinamente, se difundiu para outros setores da economia, tem se refletido de modo similar na admissão de professores da rede pública brasileira. A contratação por tempo determinado, com vínculo atípico, é admitida para atender necessidade temporária de excepcional interesse público, conforme a Constituição Federal de 1988, entretanto, esta modalidade constitui-se numa prática cada vez mais recorrente na educação brasileira. Este estudo bibliográfico e documental relaciona as mudanças no mundo do trabalho decorrentes do fenômeno da reestruturação produtiva à contratação de professores temporários na rede pública, apresentando um comparativo entre 2011 e 2018 das redes federal, estaduais e municipais no país e uma série histórica detalhada de 2004 a 2018 da rede estadual do Paraná, evidenciando a intensificação da flexibilização das contratações no setor público e a perspectiva de ampliação da precarização das condições de trabalho docente, apontando para uma ruptura da histórica tendência de se atribuir estabilidade e acesso a melhores condições de trabalho por parte dos servidores públicos.

PALAVRAS-CHAVE: Reestruturação Produtiva; Mudanças no Mundo do Trabalho; Magistério público brasileiro; Flexibilização das contratações; Professores temporários.

\begin{abstract}
The conventional way of entering into the public sector in Brazil has been consolidated by means of the approval in tender, with professional stability to the worker, however, the global trend of flexible contracting that began in the productive sector and, gradually, spread to other economy's sectors, have been similarly reflected in the admission of teachers from the Brazilian public schools. The contracting for a determined time occurs to meet temporary need of exceptional public interest, according to the Federal Constitution of 1988; however, this last modality constitutes an increasingly recurrent practice in the Brazilian Educacion. This bibliographic and documentary study relates the Changes in the Work's World resulting from Productive Restructuring to the hiring of teachers with temporary and atypical relationship in the public schools, presenting a comparison between 2011 and 2018 networks' federal, state and municipal in Brazil and also shows a detailed series historical from 2004 to 2018 of the Paraná state network, evidencing the intensification of the hiring flexibility in the public sector and the prospect of intensifying the precariousness of teaching work conditions, pointing to a break in the historical tendency to attribute stability and access to better working conditions by public servants.
\end{abstract}

\footnotetext{
${ }^{1}$ Doutoranda do Programa de Pós-Graduação em Educação, na área de Políticas Educacionais, pela Universidade Federal do Paraná (20172021). Formada em Pedagogia pela Faculdade de Campina Grande do Sul (2010), Especialista em Educação Especial e Inclusiva pelas Faculdades Espírita (2014) e Mestre em Educação pela Universidade Federal do Paraná (2013). Atualmente é Professora Adjunta na Faculdade de Campina Grande do Sul. denize fabio@ hotmail.com. Este trabalho foi realizado com apoio da Coordenação de Aperfeiçoamento de Pessoal de Nível Superior - Brasil (CAPES) - Código de Financiamento 001.
} 
KEYWORDS: Productive Restructuring; Changes in the Work's World; Brazilian public teaching profession; Flexible hiring; Temporary teachers.

\section{INTRODUÇÃO}

As mudanças no mundo do trabalho decorrentes do processo de reestruturação produtiva, ocorrido desde a década de 1970 nos países centrais e do final de 1980 no Brasil, vêm causando alterações na organização do trabalho em diferentes segmentos da economia, gerando flexibilização dos processos e mercados de trabalho (HARVEY, 1992); fragmentação, complexificação e diversificação da classe trabalhadora, enfraquecimento do poder sindical e aumento do trabalho precarizado e terceirizado (ANTUNES, 1999, 2005 e 2006); incremento do desemprego na década de 1990 (BERNARDO, 2000; POCHMANN, 2001) e ampliação de ocupações com baixa remuneração, causando queda na taxa de desemprego no início dos anos 2000 (POCHMANN, 2012). Este cenário apresenta desdobramentos no setor educacional, destacando-se a flexibilização dos contratos trabalhistas, inclusive entre os profissionais da esfera estatal, à revelia da histórica estabilidade inerente ao cargo público, como mostram os dados apresentados neste estudo.

A problemática deste artigo mostra-se relevante para as pesquisas na área de Educação e Trabalho, pois conforme Souza (1997, p. 133) a produção sociológica na área educacional tem se centrado na docência como prática pedagógica e "pouco se discute as relações entre as condições de trabalho na escola e as relações sociais a que este trabalho está submetido", nesta perspectiva, este artigo tem como objetivo apresentar um panorama acerca da contratação atípica nas redes públicas brasileiras.

Neste trabalho recorreu-se à pesquisa bibliográfica e documental, as quais possibilitam o contato com o conhecimento produzido a respeito da temática analisada; na primeira seção deste estudo buscou-se relacionar as mudanças no mundo do trabalho decorrentes do fenômeno da reestruturação produtiva à contratação de professores com vínculo temporário na rede pública. Na segunda seção se expôs a constituição do magistério enquanto profissão legítima para educar e transmitir conhecimentos às gerações futuras nas sociedades modernas, também se tratou do surgimento da profissão docente e da contratação temporária no país. Na terceira e última seção, de cunho empírico, se procedeu a exposição de dados quanto aos contratos atípicos nas redes federal, estaduais e municipais brasileiras, a partir dos microdados do Censo Escolar (INEP, 2011; 2018); na sequência, fez-se uma análise detalhada em série histórica das contratações na rede pública estadual do Paraná, com a exposição de informações coletadas no Banco de Dados on line da Secretaria de Estado da Educação do 
Paraná (SEED, 2004-2018); por fim, se procedeu a exposição de documentos oficiais da rede de ensino pesquisada que evidenciam situações indicativas de precarização das condições de trabalho dos docentes temporários.

O estudo aponta para uma ruptura da histórica predisposição de se atribuir melhores condições de trabalho aos servidores públicos em relação aos trabalhadores de outros setores da economia, bem como um reforço das tendências mundiais de terceirização e intensificação de contratações a título precário no mundo do trabalho atualmente.

\section{MUDANÇAS NO MUNDO DO TRABALHO, REESTRUTURAÇÃO PRODUTIVA E SUAS REPERCUSSÕES NO SETOR PÚBLICO}

Marx (1986) ao aplicar seu método na análise do movimento do capital descobriu a impossibilidade do capitalismo existir sem crises. Como resposta às constantes crises do sistema capitalista, a acumulação rígida da produção em massa, tida como núcleo essencial do fordismo, foi substituída, a partir dos anos 1970, pela acumulação flexível (toyotismo), a qual se apoia na "flexibilidade dos processos de trabalho, dos mercados de trabalho, dos produtos e padrões de consumo" (HARVEY, 1992, p. 29), iniciou-se então uma reestruturação capitalista, que se repercutiu sobre as mais diversas esferas da vida social.

Segundo Antunes (2005) a partir da década de 1970, devido à crise, o capital iniciou um processo de reestruturação produtiva em âmbito global, cujos reflexos mais evidentes foram: o neoliberalismo, a privatização do Estado, a desregulamentação dos direitos trabalhistas e a desmontagem do setor produtivo estatal, a partir daí, processou-se uma reestruturação da produção e do trabalho, tais iniciativas intencionavam repor os patamares anteriores de acumulação capitalista.

Conforme expõe Vasapollo (2006, p. 45) "a nova organização capitalista do trabalho é caracterizada cada vez mais pela precariedade, pela flexibilização e desregulamentação, de maneira sem precedentes para os assalariados”, na acepção do autor trata-se de um mal-estar no trabalho, pois os trabalhadores têm seus direitos desregulamentados, vivem sob apreensão constante, com medo de perderem seus postos de emprego. Trata-se, desse modo, de um processo que precariza a totalidade da vida social.

De acordo com Leite (1997) o Brasil apresenta especificidades no que se refere à reestruturação produtiva, até mesmo porque o processo de ajuste estrutural iniciou-se no país com mais de uma década de atraso em relação à economia internacional. Na década de 1980 em praticamente todo o mundo proliferavam as políticas de ajuste, enquanto o Brasil continuava a investir nos padrões anteriores, adotados no período da industrialização, em virtude da 
substituição das importações. Nesse sentido, pode-se afirmar que as repercussões da reestruturação produtiva começaram a se processar nos países centrais desde a década de 1970, já no Brasil elas surgiram a partir dos anos 80 e 90.

A crise dos anos 1970 causou impactos nos diversos setores da economia, marcadamente no setor industrial, cenário da reestruturação produtiva, com a introdução de inovações tecnológicas, organizacionais e de gestão. Já nos setores públicos, pode-se destacar a Reforma de Estado como o principal elemento decorrente desse movimento de reestruturação que, em consonância com as políticas neoliberais, têm como intuito a retomada dos padrões anteriores de acumulação capitalista.

Nesse sentido, Barbosa (2010, p. 88) afirma que as pesquisas sobre as mudanças no mundo do trabalho dão maior ênfase ao estudo da situação dos trabalhadores diretamente ligados ao mercado, entretanto, pouco se tem pesquisado sobre o servidor público no contexto da reestruturação produtiva. Diante dessa problemática o autor questiona: "como se insere este trabalhador no Mundo do Trabalho em cuja conjuntura administrativa efetiva-se o enxugamento progressivo do Estado?"; esta é uma das temáticas centrais deste estudo, a fim de permitir a compreensão acerca do fenômeno da contratação temporária de docentes brasileiros.

Pereira (1998, p. 63) afirma que, frequentemente, a Reforma Estatal é vista como um processo de redução do tamanho do Estado, que havia ampliado suas funções no século XX, crescendo tanto em termos de pessoal, como de receita e despesa. Aos poucos foi se difundindo o ideário de que "reformar o Estado significa, antes de qualquer coisa, definir seu papel, deixando para o setor privado e para o setor público não-estatal as atividades que não lhes são específicas".

No Brasil, as privatizações se iniciaram no governo Collor, tendo continuidade no governo Itamar Franco, mas encontraram seu ápice na administração de Fernando Henrique Cardoso. Nesse sentido, Fadul (1999) pontua que o processo de Reforma do Estado no Brasil associa-se, paralelamente, à ampla privatização dos serviços públicos e de empresas estatais, causando a entrada vultosa de capital estrangeiro no país, sendo este encarado pelos governos como recursos para amenizar as dívidas externas.

De acordo com Supiot (1995, p. 17) o modelo de relações de trabalho do serviço público tem uma lógica diferente do da empresa privada; em conceitos jurídicos, o setor público é caracterizado pelo estatuto, enquanto que o emprego a serviço do privado caracteriza-se pelo contrato. Nessa perspectiva, para o autor, "enquanto o contrato permite que se faça do trabalho um negócio, o estatuto, ao contrário, separa relações de trabalho e esfera comercial”, entretanto, tal distinção está desaparecendo hoje, como se pode perceber pelos conflitos recentes, visto que 
atualmente o modelo estatutário desacreditou-se ante ao modelo contratual, seja mediante a comparação entre público e privado (efeito rejeição) ou através da imitação do privado por parte do público (efeito mimetismo). Assim sendo, a contratação temporária, de certa maneira, subverte a lógica e descaracteriza o trabalho no setor público, configurando-se como uma espécie de mimetismo do setor privado, aplicando-lhe regras inerentes ao mercado.

Com o intuito de reduzir os gastos da máquina estatal foi aprovada a Lei Complementar $\mathrm{n}^{\circ} 82$ de 27 de março de 1995, conhecida como Lei Camata I, que determinou em três artigos que as despesas totais com pessoal ativo e inativo da administração direta ou indireta não poderia exceder $60 \%$ das receitas correntes líquidas da União, Estados, Distrito Federal e Municípios. Posteriormente a citada legislação foi revogada pela Lei Complementar $\mathrm{n}^{\circ} 96$ de 31 de maio de 1999, chamada de Lei Camata II, a qual possuía onze artigos, esta por sua vez, também disciplinou sobre os limites de gastos com pessoal, que não poderia ultrapassar $50 \%$ da receita corrente líquida no caso da União e 60\% da receita de Estados, Distrito Federal e Municípios.

Mais tarde foi firmada Lei Complementar $\mathrm{n}^{\circ}$ 101, aprovada em 04 de maio de 2000, conhecida como Lei de Responsabilidade Fiscal (LRF), a qual está em vigência até hoje. No que se refere ao disciplinamento das contas públicas, esta lei é mais abrangente que as anteriores, pois contém setenta e cinco artigos. Com relação aos gastos com pessoal, mantém os mesmos índices: 50\% da receita líquida da União e 60\% de Estados e Municípios, ademais, define penas para o não cumprimento dos limites estipulados na lei.

A LRF, na avaliação de Figueiredo e Nóbrega (2002), emerge após uma aguda crise financeira nos estados brasileiros nos anos 1990, num momento de total descrédito na gestão pública, devido aos diversos exemplos de descalabro financeiro, que conduziam ao endividamento público em decorrência de elevadas despesas de custeio, o que veio a exigir dos gestores públicos uma nova forma de conduta na administração da coisa pública. Os autores ainda afirmam que uma das causas da piora fiscal do Estado esteve diretamente ligada ao aumento dos gastos advindos do funcionalismo público, que após a promulgação da Constituição de 1988 cresceu substancialmente.

De acordo com Rigolin (2002) dentre os diversos temas tratados pela LRF, merece destaque a política de planejamento e limitação de despesas relativas aos gastos com vencimentos e salários dos servidores públicos. Se for verificado que foi excedido o percentual de 95\% do limite máximo a ser gasto com pessoal, passa a ser proibido: a) concessão de vantagens e aumento de pessoal, salvo se for decisão judicial ou por força de ordem constitucional; b) criação de novos cargos, empregos ou funções; c) alteração da estrutura das 
carreiras com aumento de despesa; d) contratação de horas extras do pessoal; e) preenchimento de cargo, emprego ou função, salvo em tratando de educação, saúde e segurança; entretanto, “quanto a esta última exceção, mesmo para a educação, a saúde e a segurança haverá de ser observado o limite total de despesas com pessoal para cada ente público e nessas três hipóteses a lei admitiu apenas ultrapassar a denominada 'reserva de prudência' de 5\%”, que precisa ser observada nos demais casos de admissões para outras áreas (RIGOLIN, 2002, p. 89). Assim sendo, as citadas áreas sociais também não podem exceder o limite máximo a ser gasto com pessoal na esfera pública.

Nesse contexto de transformações no setor público, Cardoso Jr. (2002) esclarece que em outubro de 1999, foi editada a Lei $\mathrm{n}^{\circ}$ 9.849, a qual altera sete artigos da Lei $\mathrm{n}^{\circ} 8.745$ de dezembro de 1993, que dispõe sobre a contratação por tempo determinado para atender a necessidades temporárias de interesse público, permitindo a prorrogação de contratos, a recontratação daqueles que haviam sido contratados anteriormente, além de incrementar as possíveis atividades sujeitas à contratação por tempo determinado.

O processo de reestruturação produtiva tem trazido consequências para a classe trabalhadora em geral, inclusive em setores não vinculados à esfera produtiva; dessa forma, até mesmo o setor público caracterizado, sobretudo, pela estabilidade e a garantia dos direitos trabalhistas, vem sendo impactado pela tendência de flexibilização dos contratos de trabalho, tal como se processa no setor produtivo. Entender como esse processo tem se refletido no funcionalismo público é fundamental para compreender a tendência de ampliação das contratações temporárias nas redes públicas de ensino no país; na próxima seção se buscará apresentar a constituição da profissão docente e da contratação atípica no Brasil.

\section{O SURGIMENTO DA PROFISSÃO DOCENTE E DA CONTRATAÇÃo TEMPORÁRIA NO BRASIL}

A educação tem papel fundamental nas sociedades, pois produz a humanidade construída pelos homens em cada indivíduo singular (SAVIANI, 2007); os professores são os profissionais devidamente reconhecidos como responsáveis pela transmissão de saberes sistematizados e institucionalizados, considerando que o ensino escolar há mais de dois séculos constitui-se na forma dominante de socialização e de formação (GATTI; BARRETO, 2009). Assim sendo, evidencia-se que a docência é um dos ofícios mais antigos das sociedades modernas, suas origens remontam o momento constitutivo do Estado-Nação capitalista, em meados do século XIX (FANFANI, 2007). 
De acordo com Oliveira (2010) em suas origens o ato de ensinar estava vinculado à vocação ou sacerdócio, com o desenvolvimento das sociedades modernas, o magistério passou a ser constituído por um corpo de trabalhadores que historicamente foi se orientando rumo à profissionalização, tal conceito resulta da forma racional-burocrática de organização do Estado, que possibilitou a estruturação dos serviços públicos; os sistemas escolares modernos surgem da organização deste aparato estatal e se organizam de maneira dependente dele.

A constituição da profissão docente no Brasil se deu na mesma proporção em que os sistemas escolares foram sendo ampliados no país, tal função foi sendo normatizada a partir do momento em que o Estado tomou para si o controle da escola, devido à necessidade de promover escolarização no país, em virtude do processo de modernização da sociedade brasileira (WEBER, 2003).

De acordo com Nascimento e Lima (2001, p. 14) após a expulsão e o confisco dos bens dos missionários jesuítas em 1759, o Marquês de Pombal adotou uma política de oferta de instrução gratuita desenvolvida por professores assalariados, os chamados mestres régios, que eram pagos com a receita do subsídio literário, tal imposto era cobrado dos açougueiros, alambiques e outros estabelecimentos, a fim de financiar o ensino público, porém quando a realeza não autorizava a contratação de tais professores ou não havia a arrecadação do subsídio literário, cessava-se a oferta de ensino, o que demonstra que este sistema era descontínuo.

Neste período instituíram-se os concursos públicos, Vicentini e Lugli (2009, p.69) esclarecem que a "instituição de concursos para a seleção de docentes inicia-se quando a tarefa do ensino é assumida pelo Estado, durante as Reformas Pombalinas em Portugal e suas colônias [...], o processo de seleção de professores iniciou-se em 1760", sendo aplicada uma prova de gramática e outra de matemática, caso o candidato fosse aprovado, receberia um documento que o autorizava a ensinar. As autoras pontuam ainda que após a aprovação no certame, o cargo era vitalício, a menos que o professor decidisse mudar de localidade, perdendo o direito de lecionar. Assim, a estabilidade do vínculo empregatício, que é uma das principais características das relações de trabalho docente no setor público, garantida mediante aprovação em concurso, tem suas origens no século XVIII.

Naquele período ninguém podia lecionar sem possuir a licença conferida pelo concurso público, entretanto, "devido tanto à falta de interesse dos professores portugueses de deslocarem-se para a colônia, como a inexistência de pessoas plenamente habilitadas no Brasil, resultou na atribuição de aulas a professores substitutos brasileiros, que já eram maioria no século XVIII" (VICENTINI; LUGLI, 2009, p. 70). 
A primeira Lei geral sobre Educação do país data de 15 de outubro de 1827 e determinou a constituição de um sistema escolar no Brasil, determinando que:

Art. 1ํㅡㄹ todas as cidades, vilas e lugares mais populosos, haverão as escolas de primeiras letras que forem necessárias. [...]

Art. 7ํ Os que pretenderem ser providos nas cadeiras serão examinados publicamente perante os Presidentes, em Conselho; e estes proverão o que for julgado mais digno e darão parte ao Governo para sua legal nomeação. [...]

Art. 14. Os provimentos dos Professores e Mestres serão vitalícios; mas os Presidentes em Conselho, a quem pertence a fiscalização das escolas, os poderão suspender e só por sentenças serão demitidos, provendo interinamente quem substitua.

Assim, com o artigo $1^{\circ}$ da referida lei, ao determinar que houvesse a quantidade necessária de escolas nas cidades mais populosas, subentende-se que o ensino sofreria um processo de ampliação para atender às novas demandas da sociedade. Dessa forma, de acordo com Vicentini e Lugli (2009, p. 15), a constituição do magistério no caso brasileiro, deve ser compreendido no âmbito da difusão do modelo escolar de educação, o qual se intensificou a partir do século XIX.

No que tange à forma de contratação dos professores, no artigo $7^{\circ}$ está claramente expresso a necessidade da instituição de exames públicos (concursos) para garantir legal nomeação, a qual seria vitalícia, ou seja, desde aquela época já era garantida a estabilidade daqueles que fossem aprovados nos exames.

Observa-se no artigo 14 a consolidação de um precedente para a contratação de profissionais não concursados, pois caso um efetivo fosse suspenso ou demitido, os Presidentes em Conselho, responsáveis pela fiscalização das escolas, deveriam prover interinamente um substituto. Ou seja, o interino caracterizado, sobretudo, pelo caráter provisório de seu vínculo, substituiria o efetivo até que um novo aprovado nos exames assumisse o cargo, tal qual ainda ocorre com os professores contratados em regime temporário no país.

A partir dos fins do século XIX, à medida que as redes oficiais de ensino foram se consolidando no país, a categoria docente deparou-se com diferentes tipos de vínculos empregatícios, uma vez que a contratação dos docentes poderia ocorrer em caráter efetivo, com a aprovação ou promoção em concurso público ou a título precário, o que gerava níveis distintos de remuneração, influenciando o estatuto socioprofissional da categoria e a organização dos próprios sistemas educacionais (VICENTINI; LUGLI, 2009).

Com a ampliação do sistema escolar durante o regime militar (1964-1985) o perfil do professorado se alterou, pois os profissionais do magistério deixaram de se originar exclusivamente das classes médias urbanas e frações das elites, passando a incorporar também membros das camadas populares, assim sendo, a partir de um processo de mobilidade, tanto 
ascendente como descendente, a nova categoria formada por essas duas frações foi submetida a condições de vida e de trabalho marcadas pelo arrocho salarial, de maneira que a profissão passou a sofrer uma crise de identidade; para os autores, "a proletarização do professorado não significou apenas o empobrecimento econômico, mas também a depauperação do próprio capital cultural que a antiga categoria possuía” (FERREIRA JR.; BITTAR, 2006, p. 1162).

Assim sendo, seria um equívoco acreditar que esta categoria social tem permanecido idêntica ao longo do tempo, mas ao contrário, seu significado e função social têm mudado conforme o ritmo das grandes transformações que caracterizaram o desenvolvimento de cada sociedade nacional (FANFANI, 2007).

A ampliação física das redes públicas e privadas de ensino demandaram o aumento dos quadros necessários para tal atendimento, concomitantemente há uma expansão das tensões vinculadas às questões salariais, às condições de trabalho, às propostas pedagógicas, etc. (CAMARGO; JACOMINI, 2011).

Para Vicentini e Lugli (2009, p. 24) não é possível contar a história da profissão docente no Brasil como se os professores constituíssem uma categoria homogênea, pois a história da docência brasileira não corresponde a uma história contínua de progressiva profissionalização, uma vez que foi perpassada por momentos de perda de autonomia, de tal forma que, "como se trata de um grupo social tão diverso em seu interior e submetido a condições tão distintas por todo o país, [...] essa história contém ao mesmo tempo processos profissionais e não profissionais, dependendo do lugar e do grupo para o qual se atente"; considerando tal constatação, na terceira seção deste ensaio será apresentado um panorama acerca da contratação temporária nas redes públicas brasileiras nos anos 2000.

\section{A CONTRATAÇÃO TEMPORÁRIA DE DOCENTES NAS REDES PÚBLICAS NO BRASIL}

De acordo com Fanfani (2007) a docência é um ofício público em mais de um sentido, primeiro por sua função estratégica de interesse geral e, segundo, porque no essencial é regulamentado e financiado pelo Estado; em virtude das transformações atuais, os agentes do Estado social, tanto professores quanto outros prestadores de serviços sociais têm passado a formar parte do grupo dos 'perdedores da transformação', isto porque, em síntese, a maioria dos Estados deve enfrentar maiores, novas e mais complexas demandas sociais de conhecimento, justiça, seguridade, assistência social, etc., sem contar com recursos, tanto financeiros como tecnológicos, normativos e humanos, necessários e adequados, o resultado tenderá a ser o empobrecimento dos serviços e servidores públicos. 
As contratações atípicas vêm se tornando cada vez mais recorrentes nos diversos setores da economia, trazendo consequências para os trabalhadores em geral. Essas formas atípicas de contratação compreendem os "contratos de trabalho por tempo determinado, trabalho em tempo parcial, interinidade, contratos mediante estatuto particular sem direitos sociais, que atingem hoje grandes proporções" (CASTEL, 1998, p. 514), assim sendo, sob esta perspectiva, o professor contratado em regime temporário na educação brasileira constitui-se num trabalhador atípico. Ainda que a nomenclatura varie nas diferentes redes do Brasil, basicamente há duas formas de contratação: uma por meio de concurso público que garante estabilidade profissional e outra atípica, não estável, que se refere à contratação temporária.

A Constituição da República Federativa do Brasil de 1988 determina em seu artigo 37, inciso II, que “a investidura em cargo ou emprego público depende de aprovação prévia em concurso público de provas ou de provas e títulos", entretanto, na sequência, o inciso IX prevê que "a lei estabelecerá os casos de contratação por tempo determinado para atender a necessidade temporária de excepcional interesse público". Dessa forma, evidencia-se que a admissão temporária na esfera pública, encontra respaldo legal, desde que se trate de contratação para o atendimento de situações atípicas.

Ademais o artigo 206, parágrafo V, da referida Constituição Federal, determina que o ensino no país seja ministrado com base no princípio da "valorização dos profissionais da educação escolar, garantidos, na forma da lei, planos de carreira, com ingresso exclusivamente por concurso público de provas e títulos, aos das redes públicas”. O que corrobora para evidenciar que a admissão temporária, constitui-se numa forma excepcional de contratação para o ingresso no magistério público.

No âmbito federal, a contratação de pessoal temporário a que faz alusão o art. 37, inciso IX da Constituição Federal, foi regulamentada pela Lei no 8.745 de 09 de dezembro de 1993, a qual estabelece em seu artigo $1^{\circ}$ que "para atender a necessidade temporária de excepcional interesse público, os órgãos da Administração Federal direta, as autarquias e as fundações públicas poderão efetuar contratação de pessoal por tempo determinado, nas condições e prazos previstos nesta Lei”.

De acordo com o artigo $2^{\circ}$, inciso IV da citada lei, dentre as situações que configuram necessidade temporária de excepcional interesse público destaca-se a admissão de professor substituto para suprir cargos vagos, afastamentos ou licenças, desde que o candidato tenha se submetido a processo seletivo simplificado, ou seja, trata-se de uma situação transitória, até a realização de concurso público. 
Tabela 1: Quantidade de professores da rede pública e seus respectivos vínculos (por dependência administrativa - Dados Gerais do Brasil - 2011/2018) ${ }^{2}$

\begin{tabular}{|c|c|c|c|c|c|c|c|c|c|c|}
\hline \multirow[b]{2}{*}{$\begin{array}{l}\text { Centro- } \\
\text { Oeste }\end{array}$} & \multicolumn{5}{|c|}{ Efetivo } & \multicolumn{5}{|c|}{ Atípico } \\
\hline & 2011 & $(\%)$ & 2018 & $(\%)$ & $\begin{array}{c}\text { Taxa } \\
\text { de } \\
\text { cresc. }\end{array}$ & 2011 & $(\%)$ & 2018 & $(\%)$ & $\begin{array}{c}\text { Taxa } \\
\text { de } \\
\text { cresc. }\end{array}$ \\
\hline Federal & 6.541 & 87,3 & 11.802 & 79,6 & 80,4 & 888 & 11,8 & 3.030 & 20,4 & 241,2 \\
\hline Estadual & 323.669 & 69,6 & 223.626 & 47,5 & $-30,9$ & 140.476 & 30,2 & 247.280 & 52,5 & 76,0 \\
\hline Municipal & 123.323 & 64,3 & 132.266 & 67,2 & 7,3 & 61.845 & 33,3 & 64.479 & 32,8 & 4,3 \\
\hline \multirow[b]{2}{*}{ Nordeste } & \multicolumn{5}{|c|}{ Efetivo } & \multicolumn{5}{|c|}{ Atípico } \\
\hline & 2011 & $(\%)$ & 2018 & $(\%)$ & $\begin{array}{c}\text { Taxa } \\
\text { de } \\
\text { cresc. }\end{array}$ & 2011 & $(\%)$ & 2018 & $(\%)$ & $\begin{array}{c}\text { Taxa } \\
\text { de } \\
\text { cresc. }\end{array}$ \\
\hline Federal & 21.248 & 88,6 & 42.856 & 89,1 & 101,7 & 2.747 & 11,4 & 5.248 & 10,9 & 91,0 \\
\hline Estadual & 692.018 & 66,7 & 614.318 & 63,4 & $-11,2$ & 345.768 & 33,3 & 355.044 & 36,6 & 2,7 \\
\hline Municipal & 855.367 & 76,2 & 891.320 & 71,6 & 4,2 & 267.729 & 23,8 & 353.505 & 28,4 & 32,0 \\
\hline \multirow[b]{2}{*}{ Norte } & \multicolumn{5}{|c|}{ Efetivo } & \multicolumn{5}{|c|}{ Atípico } \\
\hline & 2011 & $(\%)$ & 2018 & $(\%)$ & $\begin{array}{c}\text { Taxa } \\
\text { de } \\
\text { cresc. }\end{array}$ & 2011 & $(\%)$ & 2018 & $(\%)$ & $\begin{array}{c}\text { Taxa } \\
\text { de } \\
\text { cresc. }\end{array}$ \\
\hline Federal & 8.156 & 85,4 & 15.046 & 85,7 & 84,5 & 1.398 & 14,6 & 2.513 & 14,3 & 79,8 \\
\hline Estadual & 343.936 & 73,6 & 383.774 & 71,9 & 11,6 & 123.390 & 26,4 & 149.929 & 28,1 & 21,5 \\
\hline Municipal & 218.242 & 65,4 & 252.974 & 65,6 & 15,9 & 115.269 & 34,5 & 132.810 & 34,4 & 15,2 \\
\hline \multirow[b]{2}{*}{ Sudeste } & \multicolumn{5}{|c|}{ Efetivo } & \multicolumn{5}{|c|}{ Atípico } \\
\hline & 2011 & $(\%)$ & 2018 & $(\%)$ & $\begin{array}{c}\text { Taxa } \\
\text { de } \\
\text { cresc. }\end{array}$ & 2011 & $(\%)$ & 2018 & $(\%)$ & $\begin{array}{c}\text { Taxa } \\
\text { de } \\
\text { cresc. }\end{array}$ \\
\hline Federal & 20.827 & 75,0 & 37.427 & 75,2 & 79,7 & 6.947 & 25,0 & 12.328 & 24,8 & 77,5 \\
\hline Estadual & 1.521 .848 & 81,8 & 1.355 .006 & 68,6 & $-11,0$ & 338.339 & 18,2 & 619.321 & 31,4 & 83,0 \\
\hline Municipal & 909.489 & 77,9 & 1.066 .220 & 77,7 & 17,2 & 257.625 & 22,1 & 305.411 & 22,3 & 18,5 \\
\hline \multirow[b]{2}{*}{ Sul } & \multicolumn{5}{|c|}{ Efetivo } & \multicolumn{5}{|c|}{ Atípico } \\
\hline & 2011 & $(\%)$ & 2018 & $(\%)$ & $\begin{array}{c}\text { Taxa } \\
\text { de } \\
\text { cresc. }\end{array}$ & 2011 & $(\%)$ & 2018 & $(\%)$ & $\begin{array}{c}\text { Taxa } \\
\text { de } \\
\text { cresc. }\end{array}$ \\
\hline Federal & 10.429 & 83,0 & 19.435 & 82,4 & 86,4 & 2.129 & 17,0 & 4.149 & 17,6 & 94,9 \\
\hline Estadual & 528.602 & 59,4 & 495.251 & 58,5 & $-6,3$ & 360.594 & 40,6 & 350.903 & 41,5 & $-2,7$ \\
\hline Municipal & 378.170 & 77,9 & 468.648 & 79,2 & 23,9 & 107.266 & 22,1 & 122.711 & 20,8 & 14,4 \\
\hline \multirow[b]{2}{*}{ Brasil } & \multicolumn{5}{|c|}{ Efetivo } & \multicolumn{5}{|c|}{ Atípico } \\
\hline & 2011 & $(\%)$ & 2018 & $(\%)$ & $\begin{array}{c}\text { Taxa } \\
\text { de } \\
\text { cresc. }\end{array}$ & 2011 & $(\%)$ & 2018 & $(\%)$ & $\begin{array}{c}\text { Taxa } \\
\text { de } \\
\text { cresc. }\end{array}$ \\
\hline Federal & 67.201 & 82,6 & 126.566 & 82,3 & 88,3 & 14.175 & 17,4 & 27.268 & 17,7 & 92,4 \\
\hline Estadual & 3.410 .073 & 72,3 & 3.071 .975 & 64,1 & $-9,9$ & 1.309 .199 & 27,7 & 1.722 .477 & 35,9 & 31,6 \\
\hline Municipal & 2.484 .591 & 75,4 & 2.811 .428 & 74,2 & 13,2 & 810.526 & 24,6 & 978.916 & 25,8 & 20,8 \\
\hline
\end{tabular}

Fonte: Censo Escolar - INEP/MEC (2011 e 2018). Dados tabulados pela autora.

Na Tabela 1 é possível observar que em todo o Brasil a rede federal apresenta os menores percentuais de temporários, 17,4\% em 2011 passando para 17,7\% em 2018, seguida pelas redes municipais que ampliaram de $24,6 \%$ para $25,8 \%$ nos períodos observados, já a maior quantidade de contratações atípicas se dá nas redes estaduais, com incremento de 8,2\% (de $27,7 \%$ para $35,9 \%$ ) nos anos analisados.

Ao desagregar os dados evidencia-se que entre 2011 e 2018 a rede federal é a que mais se expandiu numericamente, conforme comprovam as elevadas taxas de crescimento

\footnotetext{
${ }^{2}$ Os dados quanto ao vínculo empregatício estão disponíveis somente a partir do ano de 2011. Foram considerados como professores com vínculo atípico com a rede pública aqueles contratados sem a realização de concurso público, e que, portanto, não possuem estabilidade profissional, foram agregados os seguintes vínculos: temporários, terceirizados e celetistas.
} 
acima de $75 \%$, de forma que o número de efetivos praticamente dobra em todas as regiões, assim como o de atípicos (à exceção do Centro-Oeste, onde estes últimos quase quadruplicam, gerando uma taxa de crescimento de $241,2 \%$ no período).

Nas redes estaduais há um crescimento no percentual de contratos atípicos em todas as regiões brasileiras, sendo que no Sudeste e Centro-Oeste estes praticamente dobraram, gerando taxas de crescimento de $83,0 \%$, e 76,0\%, respectivamente; a única taxa de crescimento negativa de atípicos foi no Sul devido à queda numérica de contratados, todavia o quantitativo de efetivos também se reduziu, o que representa um decréscimo geral do quadro de pessoal. Já entre os efetivos somente o Norte não apresenta taxa negativa de crescimento, com exceção do Sul onde também há taxa negativa entre atípicos, todas as outras regiões têm taxa de crescimento positiva de temporários, o que significa a priorização deste tipo de contratação nestas regiões.

As redes municipais têm pouca alteração percentual de um ano para o outro, apresentando taxa de crescimento positiva de até 23,9\% em ambos os vínculos nos anos analisados, evidenciando ampliação geral do quadro de pessoal. Entre os atípicos, a taxa de crescimento varia de 4,3\% no Centro-Oeste a 32,0\% no Nordeste, isto é, ainda que o percentual tenha se mantido constante, o quantitativo numérico vem sendo incrementado à medida que a rede vem sendo expandida, porém a taxa de crescimento de atípicos é menor (Centro-Oeste e Sul) ou igual (Norte e Sudeste) à de efetivos, à exceção do Nordeste, onde a taxa de crescimento de atípicos chega a 32,0\% contra 4,2\% de efetivos, o que evidencia que apenas nesta última região vem ocorrendo a ampliação deste tipo de contratação.

Diante do exposto, observa-se que as redes públicas são compostas, de um lado por funcionários efetivos admitidos mediante concurso público, que usufruem de estabilidade e de direitos trabalhistas historicamente conquistados, que na acepção de Harvey (1992) integrariam o 'núcleo duro' dos servidores públicos no Estado; e de outro, encontram-se os trabalhadores atípicos, os quais não têm vínculo estável e não possuem os mesmos direitos dos estatutários, seria o chamado 'grupo periférico' dos servidores públicos; tal situação, evidencia que o setor público vem utilizando uma prerrogativa similar a dos setores produtivos, apontada por diversos autores anteriormente mencionados, no que tange à crescente contratação flexibilizada no mundo do trabalho atualmente.

É importante considerar o fato de que o Brasil é um país federativo, com distribuição de responsabilidades entre três instâncias (União, estados e municípios), cada qual com suas respectivas autonomias, o que impacta na regulamentação de carreiras e salários dos professores no âmbito das gestões públicas, gerando dificuldade de se mensurar precisamente 
as condições de carreira e remuneração dos trabalhadores em educação (GATTI; BARRETO, 2009).

Segundo a legislação brasileira (art. 211 da Constituição de 1988 e art. $8^{\circ}$ da Lei de Diretrizes e Bases da Educação Nacional), a União, os Estados, o Distrito Federal e os Municípios organizarão seus respectivos sistemas de ensino em regime de colaboração, assim sendo, é possível encontrar uma infinidade de situações vinculadas à contratação de profissionais, haja vista que o território brasileiro é dividido em 27 unidades federativas que compõem cinco regiões e subdividem-se em 5.570 municípios, sendo que cada um desses entes tem autonomia para legislar e organizar suas redes e/ou sistemas de ensino. Considerando a peculiaridade do caso brasileiro, optou-se por expor uma série histórica detalhada de 2004 a 2018, além de informações sobre a contratação de professores temporários, da rede pública estadual do Paraná, na região Sul do país.

\section{O CASO DA REDE ESTADUAL DO PARANÁ}

No âmbito do magistério estadual paranaense na década de 1990 e início dos anos 2000 coexistiam quatro formas de contratação: efetivos, celetistas, professores admitidos pela empresa Paranaeducação e pelo Processo Seletivo Simplificado (PSS), sendo os três últimos em caráter temporário, sem vínculo estável com o Estado.

Na Tabela 2 a seguir é possível perceber que a partir de 2006 predomina a existência basicamente de dois vínculos empregatícios: estatutários (QPM), admitidos mediante concurso público, com vínculo estável; e temporários, contratados via PSS, sem estabilidade, sem acesso a planos de carreira, gratificações, entre outros direitos conquistados pela categoria.

Nos anos analisados, a quantidade de admissões temporárias no decorrer do ano letivo oscilou entre 22 a 37\%. Mesmo em anos posteriores à realização de concursos públicos (2003, 2004, 2007 e 2013) essa quantia não diminuiu, ao contrário, a partir dos dois últimos concursos pode-se perceber um incremento de temporários. 
Tabela 2: Quantidade de professores da rede pública estadual e seus respectivos vínculos (Dados gerais do Estado do Paraná - 2004/2018)

\begin{tabular}{|c|c|c|c|c|c|c|c|c|c|}
\hline \multirow{2}{*}{$\mathrm{ANO}^{3}$} & \multirow{2}{*}{$\begin{array}{l}\text { TOTAL DE } \\
\text { PROF }^{\mathbf{S}}\end{array}$} & \multicolumn{2}{|c|}{$\mathbf{Q P M}^{4}$} & \multicolumn{2}{|c|}{$\mathrm{CLT}^{5}$} & \multicolumn{2}{|c|}{ PR Educação ${ }^{6}$} & \multicolumn{2}{|c|}{ PSS } \\
\hline & & TOTAL & $\%$ & TOTAL & $\%$ & TOTAL & $\%$ & TOTAL & $\%$ \\
\hline 2004 & 51.631 & 34.471 & 66,8 & 6.680 & 12,9 & 1.073 & 2,1 & 9.407 & 18,2 \\
\hline 2005 & 50.668 & 38.538 & 76,1 & 5.127 & 10,1 & 636 & 1,2 & 6.367 & 12,6 \\
\hline 2006 & 56.803 & 43.871 & 77,2 & 01 & 0,0 & 14 & 0,02 & 12.917 & 22,7 \\
\hline 2007 & 59.435 & 43.677 & 73,5 & 01 & 0,0 & 09 & 0,02 & 15.748 & 26,5 \\
\hline 2008 & 62.125 & 42.922 & 69,1 & 01 & 0,0 & 06 & 0,01 & 19.196 & 30,9 \\
\hline 2009 & 69.410 & 46.405 & 66,8 & 01 & 0,0 & 04 & 0,0 & 23.000 & 33,1 \\
\hline 2010 & 73.455 & 46.125 & 62,7 & 01 & 0,0 & 02 & 0,0 & 27.327 & 37,2 \\
\hline 2011 & 73.873 & 46.122 & 62,4 & 01 & 0,0 & 02 & 0,0 & 27.748 & 37,5 \\
\hline 2012 & 75.021 & 51.699 & 68,9 & 0 & 0,0 & 02 & 0,0 & 23.320 & 31,1 \\
\hline 2013 & 79.497 & 50.580 & 63,6 & 0 & 0,0 & 02 & 0,0 & 28.915 & 36,4 \\
\hline 2014 & 79.014 & 49.692 & 62,9 & 0 & 0,0 & 02 & 0,0 & 29.320 & 37,1 \\
\hline 2015 & 74.512 & 51.940 & 69,7 & 0 & 0,0 & 02 & 0,0 & 22.570 & 30,3 \\
\hline 2016 & 77.774 & 50.673 & 65,1 & 0 & 0,0 & 02 & 0,0 & 27.099 & 34,9 \\
\hline 2017 & 69.932 & 48.892 & 69,9 & 0 & 0,0 & 02 & 0,0 & 21.038 & 30,1 \\
\hline 2018 & 67.076 & 46.497 & 69,3 & 0 & 0,0 & 02 & 0,0 & 20.577 & 30,7 \\
\hline
\end{tabular}

Fonte: SEED-PR. Dados tabulados pela autora.

Os professores da Educação Básica da rede pública estadual do Paraná contratados em regime especial são admitidos mediante um processo de seleção simplificado, seus contratos de trabalho, em geral, começam no início de cada ano e são encerrados ao término do ano letivo, sem garantias de posterior recontratação no ano seguinte, assim sendo, tais profissionais não recebem remuneração durante o período de férias escolares (FERREIRA, 2013).

No Paraná a contratação temporária está prevista na própria Constituição Estadual, que seguindo os moldes da federativa, prevê em seu artigo $27^{\circ}$, inciso II, que a investidura em cargo ou emprego público exige aprovação prévia em concurso, todavia, o inciso IX do mesmo artigo, determina que uma Lei Complementar regulamente os casos de contratação interina, para o atendimento de necessidade temporária de excepcional interesse público, normatizando ainda que haja testes seletivos, ressalvados os casos de calamidade pública e que a duração do contrato tenha prazo máximo de dois anos. A legislação especial que regulamenta a contratação de temporários atualmente no Estado do Paraná é a Lei Complementar nº 108 de 18 de maio de

\footnotetext{
${ }^{3}$ Os dados estão disponíveis somente a partir do ano de 2004; o mês de referência é novembro, considerado por Ferreira (2013) como o ápice anual das contratações.

${ }^{4}$ Somatória dos vínculos QPM-P, QPM-E e QUP (estatutários).

${ }^{5}$ Somatória dos vínculos TF57-L, TF58-L, TF57-T e TF58-T (celetistas).

${ }^{6}$ Somatória dos vínculos PEPR e PEPE (ParanaEducação)
} 
2005 (tendo alguns de seus dispositivos alterados pela Lei Complementar $n^{\circ} 177$ de 18 de julho de 2014) e o Decreto ${ }^{\circ} 4.512$ de 01 de abril de 2009.

Acerca do prazo de duração do contrato as referidas Leis normatizam que seja de doze meses, podendo ser prorrogado por quantas vezes forem necessárias, desde que não ultrapasse o limite máximo de dois anos. Entretanto, em pesquisa realizada por Ferreira (2013), há casos de profissionais que permaneceram por mais de uma década como temporários, tendo seus contratos encerrados a cada dois anos e iniciando um novo contrato após esse prazo, o que demonstra que a legislação vem sendo burlada no estado.

Diante do exposto, destaca-se a existência de duas categorias de trabalhadores no âmbito do magistério público, quanto ao tipo de vínculo empregatício: estáveis e atípicos (temporários), ambos realizam trabalhos iguais ou similares, porém estes últimos estão submetidos à instabilidade inerente à sua forma de contratação, intensificando ainda mais a precarização de suas condições de trabalho. Tal situação corrobora com a perspectiva defendida por Ferreira (2013) de que a existência de diversos vínculos empregatícios dentro da mesma categoria representa estratificação e fragmentação da classe, ainda que efetivos e temporários sejam profissionais da mesma rede, por possuírem diferentes vínculos, não comungam dos mesmos interesses e não lutam pelos mesmos ideais, o que compromete o poder reivindicatório e a organização da categoria.

$\mathrm{Na}$ rede de ensino estadual do Paraná ocorreu uma situação problemática estabelecida pela mesma Resolução nº 113/2017 em relação à hora-atividade, determinou-se que na distribuição de aula aos detentores de cargos de 20 horas semanais lhes fossem atribuídas 15 aulas e 05 horas-atividade, diminuindo de 07 para 05 horas-atividade semanais. O impacto da redução da hora-atividade é visível na Tabela 2, pois de 2016 para 2018 houve a redução de praticamente 6,5 mil temporários, haja vista que os efetivos assumiram mais aulas.

Entretanto, a Resolução $n^{\circ}$ 15/2018 apresentou outra redação sobre a polêmica das horas-atividade para o novo ano letivo, estabelecendo que aos detentores de cargos de 20h/semanais seriam atribuídas 15 aulas de 50 minutos (correspondentes a $12 \mathrm{~h}$ e $30 \mathrm{~min}$ de interação com educando), 05 horas-atividade de 50 minutos cumpridas na instituição de ensino e 04 horas-atividade de 50 minutos cumpridas em local de livre escolha (totalizando $07 \mathrm{~h}$ e 30 min de horas-atividade), ou seja, houve uma ampliação da jornada do professor para 24 horas/aula para cumprimento das 20 horas/relógio, ainda que este entendimento nunca tenha sido usual na mencionada rede.

Conforme Tardif e Lessard (2012, p. 111) a carga de trabalho do professor não pode ser mensurada apenas nos momentos de interação com alunos, devido à necessidade de 
preparação de aula, elaboração e correção de avaliações/tarefas, etc. Nesse sentido, a redução das aulas destinadas à hora-atividade tende a intensificar a carga de trabalho dos professores, ferindo uma conquista advinda de constantes reivindicações vinculadas à valorização dos profissionais da Educação Básica, assegurada por meio de instrumentos jurídico-legais, como o Piso Salarial Profissional Nacional (PSPN).

O Edital n ${ }^{\circ} 72 / 2017$ publicado pelo Governo do Estado do Paraná estabeleceu instruções destinadas à realização de contratações atípicas para o ano letivo de 2018 na rede estadual, prevendo um mínimo de 10 mil vagas, ainda que a série histórica (2004-2018) evidencie praticamente o dobro e, por vezes, até o triplo deste contingente. Conforme consta na Tabela 3, houve uma redução de 13,35\% do vencimento destinado ao professor temporário com formação em nível superior.

Tabela 3: Formação, valor hora aula e remuneração do professor temporário da rede estadual do Paraná (20172018)

\begin{tabular}{l|c|r|r|r}
\hline \multicolumn{1}{c|}{ Formação } & $\begin{array}{c}\text { Valor hora/ } \\
\text { aula 2017 }\end{array}$ & $\begin{array}{c}\text { Remuneração } \\
\mathbf{2 0 1 7}^{\mathbf{7}}\end{array}$ & $\begin{array}{c}\text { Valor hora/ } \\
\text { aula 2018 }\end{array}$ & $\begin{array}{c}\text { Remuneração } \\
\mathbf{2 0 1 8}^{\mathbf{1}}\end{array}$ \\
\hline $\begin{array}{l}\text { Núvel superior } \\
\text { (Licenciatura Plena) }\end{array}$ & $\mathrm{R} \$ 15,73$ & $\mathrm{R} \$ 3.655,80$ & $\mathrm{R} \$ 13,63$ & $\mathrm{R} \$ 3.277,80$ \\
\hline Licenciatura Curta & $\mathrm{R} \$ 11,80$ & $\mathrm{R} \$ 2.948,40$ & $\mathrm{R} \$ 11,79$ & $\mathrm{R} \$ 2.946,60$ \\
\hline $\begin{array}{l}\text { Acadêmicos de 1a } \\
\text { graduação }\end{array}$ & $\mathrm{R} \$ 11,01$ & $\mathrm{R} \$ 2.806,20$ & $\mathrm{R} \$ 11,01$ & $\mathrm{R} \$ 2.806,20$ \\
\hline
\end{tabular}

Fonte: Editais n ${ }^{\circ}$ 58/2015 e n⿳0 72/2017.

Numa abordagem mais conceitual, convém destacar a diferença entre salário, vencimento e remuneração:

O salário é definido juridicamente como uma retribuição paga diretamente pelo empregador ao empregado pelo tempo de trabalho realizado [...]. Já o termo 'vencimento' é definido legalmente [...] como retribuição pecuniária pelo exercício de cargo público, com valor fixado em lei. Os vencimentos dos cargos efetivos são irredutíveis e, para cargos da mesma da mesma atribuição ou de atribuição semelhantes na esfera administrativa, é garantida isonomia. [...] A remuneração é a soma dos benefícios financeiros, dentre eles o salário, acordada por um contrato assinado entre empregado e empregador. O salário é, assim, uma parte da remuneração" (CAMARGO et al, 2009, p. 342 - sem grifos no original).

Partindo desta definição, ressalta-se que os vencimentos dos cargos efetivos são irredutíveis, entretanto, os cargos temporários não estão submetidos a esta mesma lógica, e, portanto, sofreram redução no ano de 2018 na rede estadual paranaense, o que evidencia o tratamento diferenciado dispensado aos servidores conforme seu vínculo empregatício, lesando o princípio da isonomia na esfera pública.

\footnotetext{
${ }^{7}$ Remuneração para 40hs semanais, equivalente a 180hs mensais, conforme orientações da SEED; o cálculo é composto por vencimento e auxílio transporte ( $\mathrm{R} \$ 4,58$ por hora para todos os vencimentos).
} 
Ainda nesta perspectiva, conforme Supiot (1995), no caso do regime estatutário, passa-se do salário à remuneração, que representa a contrapartida do compromisso da pessoa com o serviço prestado ao público, não tendo o valor de mercado dessa prestação como indexador financeiro, para o autor a remuneração deve ser necessária e suficiente para salvaguardar a dignidade (evitando o acúmulo de vários empregos) e a integridade (preservando-a da tentação da corrupção) do servidor; neste sentido, convém problematizar em que medida a remuneração dos profissionais temporários da educação lhes permite uma sobrevivência digna, haja vista que este trabalhador constitui-se num potencial desempregado, devido a instabilidade de seu vínculo empregatício.

\section{CONSIDERAÇÕES FINAIS}

A reestruturação produtiva processada no interior do modo de produção capitalista, a partir da década de 1970 nos países centrais e desde o final da década de 1980 no Brasil, apresenta repercussões nas diferentes esferas da vida social, afetando diretamente o mundo do trabalho, em especial, o campo do direito trabalhista, o que em muitos casos tem causado precarização dos contratos e das condições de trabalho em diferentes setores da economia.

Este artigo se propôs a discutir as mudanças no mundo do trabalho decorrentes da reestruturação produtiva e sua relação com as admissões atípicas nas redes públicas educacionais do país. Diante do exposto, pode-se constatar que a tendência de flexibilização das contratações, própria do setor produtivo, tem apresentado reflexos também no setor público, o qual atualmente vem expandindo as contratações temporárias, gerando impactos sobre as condições de trabalho deste grupo de profissionais.

Uma compreensão ampliada acerca da história da categoria docente, assim como de suas condições de trabalho, é fundamental para subsidiar o debate quanto ao significado do magistério na atualidade, por isso, este estudo se propôs a expor um panorama recente da situação vivenciada pelos professores das redes públicas do país, apontando para uma ruptura da histórica tendência de se atribuir melhores condições de trabalho aos servidores públicos em relação a trabalhadores de outros setores da economia, assim como também se percebeu um incremento da terceirização e intensificação de contratações a título precário no setor público.

É possível afirmar que a contratação temporária dos docentes das redes públicas no país emerge de um contexto mais amplo que, por sua vez, reflete as tendências atualmente presentes no mundo do trabalho, as quais mediante inúmeras mediações se associam ao movimento de reestruturação produtiva do sistema capitalista. Assim sendo, evidenciou-se que esta situação tem origens históricas, alterando-se suas condições e nomenclaturas, mas 
basicamente ambas as formas de contratação se mantêm na educação pública desde o surgimento de um sistema educacional no Brasil.

Diante da grande diversidade de situações e condições de trabalho e de emprego a que estão submetidos os professores das escolas públicas brasileiras é possível constatar que a contratação sem vínculo estável com o Estado está presente nas diferentes redes e regiões do país, mesmo que com nomenclaturas e em proporções diferenciadas, mas seguindo o mesmo princípio. Faz-se necessário ressaltar ainda que não há uniformidade nas formas de contratação temporária no Brasil, visto que a Constituição Federal determina que cada ente federado elabore leis para disciplinar a contratação em regime especial, evidenciando a necessidade de mais pesquisas na área.

\section{REFERÊNCIAS}

ANTUNES, R. Adeus ao trabalho? Ensaio sobre as metamorfoses e a centralidade do mundo do trabalho. São Paulo: Cortez; Campinas: Ed. UNICAMP, 2006.

ANTUNES, R. O caracol e sua concha: ensaios sobre a nova morfologia do trabalho. São Paulo: Boitempo, 2005.

ANTUNES, R. Os sentidos do trabalho: Ensaio sobre a afirmação e a negação do trabalho. São Paulo: Boitempo, 1999.

BARBOSA, R. T. de O. As nuances da reestruturação produtiva na administração pública: uma incipiente análise através da reforma gerencial. Revista Serviço Social \& Realidade, v. 19, n. 2, pp. 87-102, 2010

BERNARDO, J. Transnacionalização do capital e fragmentação dos trabalhadores. São Paulo: Boitempo, 2000.

BRASIL. Constituição Federal de 1988. Disponível em < http://www2.camara.leg.br/legin/fed/consti/1988/constituicao-1988-5-outubro-1988-322142publicacaooriginal-1-pl.html> Acesso em 27 jun. 2018.

BRASIL. Lei Complementar $n^{0} 101$ de 04 de maio de 2000. Disponível em <http://www2.camara.leg.br/legin/fed/leicom/2000/leicomplementar-101-4-maio-2000351480-normaatualizada-pl.pdf> Acesso em 27 jun. 2018.

BRASIL. Lei de 15 de outubro de 1827. Disponível em <http://www2.camara.leg.br/legin/fed/lei_sn/1824-1899/lei-38398-15-outubro-1827-566692publicacaooriginal-90222-pl.html> Acesso em 27 jun. 2018.

BRASIL. Lei $n^{0} 8.745$ de 09 de dezembro de 1993. Dispõe sobre a contratação por tempo determinado para atender a necessidade temporária de excepcional interesse público. Disponível em <http://www.planalto.gov.br/ccivil_03/leis/L8745cons.htm> Acesso em 27 jun. 2018. 
BRASIL. Lei $\mathbf{n}^{\mathbf{0}} \mathbf{9 . 3 9 4}$ de 20 de dezembro de 1996. Disponível em $<w w w . p l a n a l t o . g o v . b r / c c i v i l \_03 / l e i s / l 9394 . h t m>$ Acesso em 21 maio 2018.

CAMARGO, R. B. de; e JACOMINI, M. A. Carreira e salário do pessoal docente da Educação Básica: algumas demarcações legais. Revista Educação em foco, ano 14, n. 17, pp. 129-167, jul. 2011.

CAMARGO, R. B. de; GOUVEIA, A. B.; GIL, J.; e MINHOTO, M. A. P. Financiamento da educação e remuneração docente: um começo de conversa em tempos de piso salarial. Revista Brasileira de Política e Administração da Educação, v. 25, n. 2, pp. 341-361, maio/ago. 2009.

CARDOSO JR., J. C. Reforma do Estado e desregulamentação do trabalho no Brasil, nos anos 90. Revista Ensaios FEE, Porto Alegre, v. 23, n. 2, pp. 899-922, 2002.

CASTEL, R. As metamorfoses da questão social: uma crônica do salário. Petrópolis: Vozes, 1998.

FADUL, É. M. C. Reforma do Estado e serviços públicos: transformação de um modelo ou adaptação a uma nova ordem social? Revista de Administração, v. 34, n. 1, pp. 70-8, jan./mar. 1999.

FANFANI, E. T. La condición docente: análisis comparado de la Argentina,Brasil, Perú y Uruguay. Buenos Aires: Siglo XXI Editores, 2007.

FERREIRA, D. C. K. Os professores temporários da Educação Básica da Rede Pública Estadual do Paraná. 185 f. Dissertação (Mestrado em Educação) - Programa de PósGraduação em Educação. Universidade Federal do Paraná, Curitiba, 2013.

FERREIRA JÚNIOR, A.; BITTAR, M. A ditadura militar e a proletarização dos professores. Revista Educação \& Sociedade, v.27, n.97, pp. 1159-1179, set/dez. 2006.

FIGUEIREDO, C. M. e NÓBREGA, M. A. R. da. A Lei de Responsabilidade Fiscal e o Limite Prudencial: os limites máximos transitórios In: NASCIMENTO, C. V. do (coord.). Lei de Responsabilidade Fiscal: Teoria e Prática. Rio de Janeiro: América Jurídica, 2002, pp. 1-24.

GATTI, B. A.; e BARRETO, E. S. Professores do Brasil: impasses e desafios. Brasília: UNESCO, 2009.

HARVEY, D. Condição pós-moderna. São Paulo: Loyola, 1992.

LEITE, M. de P. Reestruturação Produtiva e Sindicatos: o paradoxo da modernidade. In: LEITE, M. de P. (Org). O trabalho em movimento. Campinas: Papirus, 1997, pp. 09-30.

MARX, K. O Capital: crítica da economia política. Livro I, tomo 1. São Paulo: Abril, 1986.

NASCIMENTO, F. das C. F. do; e LIMA, M. C. Terceirização na Educação: a face moderna do retrocesso. Brasília, 2001. 
OLIVEIRA, D. A. Os trabalhadores docentes e a construção política da profissão docente no Brasil. Educar em Revista, n.1, pp. 17-36, 2010.

PARANÁ. Constituição do Estado do Paraná. Disponível em < http://www.legislacao.pr.gov.br/legislacao/listarAtosAno.do?action=exibir\&codAto $=9779 \& \mathrm{c}$ odTipoAto> Acesso em 25 jun. 2017.

PARANÁ. Decreto $\mathbf{n}^{\mathbf{0}} \mathbf{4 . 5 1 2}$ de 01 de abril de 2009. Disponível em < http://www.legislacao.pr.gov.br/legislacao/listarAtosAno.do?action=exibir\&codAto $=48225 \&$ indice $=4 \&$ anoSpan $=2012 \&$ anoSelecionado $=2009 \&$ mesSelecionado $=4 \&$ isPaginado $=$ true $>$ Acesso em 25 jun. 2018.

PARANÁ. Edital $\mathbf{n}^{\mathbf{5}} \quad \mathbf{5 8 / 2 0 1 5} \quad$ - $\quad$ GS/SEED. Disponível em <http://www.educacao.pr.gov.br/arquivos/File/editais/2016/edital58_2016gsseed.pdf $>$ Acesso em 25 jun. 2018.

PARANÁ. Edital no 72/2017 - DG/SEED. Disponível em < http://appsindicato.org.br/wpcontent/uploads/2017/12/Edital-72-2017-GS-SEED-PSS-2018-PROF-Final.pdf > Acesso em 25 jun. 2018.

PARANÁ. Lei Complementar $n^{\mathbf{0}} 108$ de 18 de maio de 2005. Disponível em < http://www.legislacao.pr.gov.br/legislacao/pesquisarAto.do?action=exibir\&codAto $=7352>$ Acesso em 25 jun. 2018.

PARANÁ. Lei Complementar $n^{0} 177$ de 18 de julho de 2014. Disponível em < http://www.legislacao.pr.gov.br/legislacao/pesquisarAto.do? action=exibir\&codAto $=125019$ $\&$ codItemAto $=773821 \# 773821>$ Acesso em 25 jun. 2018.

PARANÁ. Resolução no 113/2017 - DG/SEED. Disponível em < http://www.educacao.pr.gov.br/arquivos/File/resolucoes/2017/resolucao1132017gsseed.pdf> Acesso em 25 jun. 2018.

PARANÁ. Resolução $\mathbf{n}^{\mathbf{0}} \mathbf{1 5 / 2 0 1 8}$ - DG/SEED. Disponível em < http://www.educacao.pr.gov.br/arquivos/File/resolucoes/2018/resolucao152018gsseed.pdf> Acesso em 25 jun. 2018.

PEREIRA, L. C. B. A reforma do Estado nos anos 90: lógica e mecanismos de controle. Lua Nova Revista de Cultura e Política, n. 45, pp. 49-95, 1998.

POCHMANN, M. Nova classe média? O Trabalho na base da pirâmide social brasileira. São Paulo, Boitempo, 2012.

POCHMANN, M. O emprego na globalização. São Paulo: Boitempo, 2001.

RIGOLIN, I. B. Lei de Responsabilidade Fiscal e despesas com pessoal. In: NASCIMENTO, C. V. do (coord.). Lei de Responsabilidade Fiscal: Teoria e Prática. Rio de Janeiro: América Jurídica, 2002, pp. 79-92.

SAVIANI, D. Trabalho e educação: fundamentos ontológicos e históricos. Revista Brasileira de Educação, v. 12, n. 34, pp. 252-265, jan./abr. 2007. 
SOUZA, A. N. de. Movimento sindical docente: a difícil trajetória. In: LEITE, M. de P. (Org). O trabalho em movimento. Campinas: Papirus, 1997, pp. 113-174.

SUPIOT, A. A crise do espírito de serviço público. Adverso: Revista da Associação de Docentes da UFRGS, ano V, n. 7, pp. 16-25, jul. 1995.

TARDIF, M.; LESSARD, C. O trabalho docente: elementos para uma teoria da docência como profissão de interações humanas. Petrópolis, RJ: Vozes, 2012.

VASAPOLLO, L. O trabalho atípico e a precariedade: elemento estratégico determinante do capital no paradigma pós-fordista. In: ANTUNES, R. (Org.). Riqueza e miséria do trabalho no Brasil. São Paulo: Boitempo, 2006, pp. 45-57.

VICENTINI, P. P.; LUGLI, R. G. História da profissão docente no Brasil: Representações em disputa. São Paulo: Cortez, 2009.

VIEIRA, R. de A.; e MACIEL, L. S. B. Repercussões da acumulação flexível no campo educacional: o professor temporário em questão. Revista HISTEDBR On-line, número especial, pp. 156-169, abr. 2011.

WEBER, S. Profissionalização docente e políticas públicas no Brasil. Revista Educação \& Sociedade, v. 24, n.85, pp. 1125-1154, dez. 2003.

Recebido em: 17/10/2019

Aprovado em: 10/11/2019 